\title{
DEVELOPMENT AND APPLICATION OF A PROTOCOL TO ASSESS HEALTHCARE WASTE MANAGEMENT
}

\author{
Leonardo de Lima Moura ${ }^{1, *}$, Claudio Fernando Mahler ${ }^{1}$ and Heitor Mansur Caulliraux ${ }^{2}$ \\ ${ }^{1}$ Department of Civil Engineering, COPPE, Federal University of Rio de Janeiro, Av. Horácio Macedo, 2030 - 101, Cidade Universitária, \\ RJ, 21941-450, Rio de Janeiro, Brazil \\ 2 Production Engineering Program, COPPE, Federal University of Rio de Janeiro, Av. Horácio Macedo, 2030 - 101, Cidade Universitária, \\ RJ, 21941-450, Rio de Janeiro, Brazil
}

Article Info:

Received:

10 January 2018

Revised:

19 July 2018

Accepted:

26 September 2018

Available online:

23 November 2018

Keywords:

Healthcare

Waste

Management

Assessment

Protocol

\section{ABSTRACT}

Healthcare waste management (HCWM) is a current problem in many developing countries. One of the primary steps to implement a proper HCWM process is to know the amount of healthcare waste (HCW) generated, its composition and the logistics flow. However, due to a lack of systematic protocols to facilitate the assessment of HCWM, this information cannot be obtained easily. Therefore, this study, based on a comprehensive literature review, aimed to develop a new tool for assessment of HCWM. This protocol also involves qualitative (questionnaires and observation) and quantitative (quantification and gravimetric characterization) data. Application of the protocol in a maternity hospital showed that it allows complete assessment of HCWM, especially the identification of the most significant sectors and the contribution of each one to the total HCW. We concluded that the protocol can be important for healthcare professionals and researchers to obtain information to improve HCWM.

\section{INTRODUCTION}

Poor management of healthcare waste (HCW) is an increasing problem in many developing countries as populations grow and demand for health services increases to enable improved quality of life and longer life expectancy. These countries have gaps in different stages of HCW management, especially with regard to segregation and final disposal.

Healthcare waste management (HCWM) practices vary from country to country and regionally within countries, since they depend on several factors, such as socioeconomic conditions, human and financial resources available and existing legislation and regulations. Therefore, an important step for implementation of better HCWM is knowledge of the amount of waste generated and its composition.

In developing countries, there is a lack of data about HCW generation and composition. This has encouraged research into HCW assessment in hospitals in several countries, such as Brazil (Andre et al., 2016; Souza et al., 2015; Aduan et al., 2014; Moreira and Gunther, 2012), Ethiopia (Tadesse et al., 2014; Tesfahun et al., 2014; Idowu et al., 2013; Debere et al., 2013), India (Sharma and Gupta, 2017; Hiremath et al., 2016; Kumar et al., 2014), Iran (Ghafuri and Nabidazeh, 2017; Sartaj and Aragbol, 2015; Hadipour et al., 2014; Malekahma- di and Yunesiam, 2014; Oroei et al., 2014; Koolivand et al, 2012), Nigeria (Oyekale and Oyekale, 2017; Anozie et al., 2017; Awodele et al., 2016; Oli et al., 2016; Longe, 2012) and Pakistan (Ali et al., 2017; Kumar et al., 2015).

In general, these studies used a wide variety of data collection tools, which hinders reproducibility. Therefore, this article, based on a comprehensive literature review, proposes a protocol to support the assessment of HWCM in health units.

\section{THE PROPOSED PROTOCOL FOR HCWM ASSESSMENT}

The proposed HCWM assessment protocol is divided into three steps, described next.

\subsection{Step 1: Observing the hospital routine}

The objective is to monitor the flow of patients and $\mathrm{HCW}$. In relation to places to visit, the most important are waste storage rooms and external waste shelters. In these areas it will be possible to see the hospital's infrastructure for HCWM in addition to how waste is segregated, packaged and transported. The researcher is expected to establish initial contacts with the cleaners at the hospital and to develop an understanding of how their activities are related with HCWM. 
Among the cleaning staff, the protocol involves monitoring their activities through listening, observation and annotation of their activities. Furthermore, it is important to obtain other information about HCWM from different professionals, such as doctors, nurses and pharmacists, because their different responsibilities and attitudes directly influence the HCWM, especially with regard to the adequate segregation of waste.

The data should be documented by taking daily notes for later transcription. It is also important to use photo documentation, of course with the permission of the hospital management.

Some documents that are important to analyse are the hospital's waste management plan and documents regarding external collection, treatment and final disposal, as well as the legal and regulatory rules on waste management.

At the end of this stage, the researcher should be able to describe the HCW logistics flow and the flow of patients at the hospital, identifying how much and what types of wastes are generated by each sector.

\subsection{Step 2: HCW quantification and characterization}

The objective of this stage is to obtain information regarding the amount and types of $\mathrm{HCW}$, through quantification and gravimetric characterization. This stage will be carried out concomitantly with characterization and the choice of the setting will depend on the process of each hospital, but it is usually simpler to do this at the external shelter when possible.

Regarding duration of the sampling period, according to Tesfahun et al. (2014), Tadesse and Komie (2014) and Zhang et al. (2013), seven consecutive days is the minimum necessary to obtain reliable data. After this first measurement, many researchers have monitored seasonal flow by averaging the amount of waste per patient, based on patient numbers per day, week or month.

After the mapping the HCW flow and generation sectors, the following steps should be carried out, adapted from the Guide for Internal Solid Waste Management in Health Facilities, published in 1997 by the Pan-American Health Organization (PAHO), as shown in Figure 1, for HCW quantification.

As observed in Figure 1, the first step is to follow a collector. After the bags are collected and labelled, the researcher must separate the bags by sector and leave them in containers.

At the end of the collection, the researcher must weigh each bag from each sector separately by waste group according national legislation. In Table 1, we present the Brazilian HCW classification based on two federal resolutions (ANVISA, 2004; CONAMA, 2005) and some examples of each group.

For gravimetric characterization, we suggest that source separation is the best procedure. In the gravimetric characterization, initial consideration should go to which HCW group will be analysed, in order to minimize occupational risks. In addition, to reduce the occupational hazards related to this procedure, the activity should be performed using all personal protective items (PPIs), in the shortest possible time and in the presence of the smallest number of people.

\subsection{Step 3: Application of questionnaires and inter- views}

The objective is to obtain data that may not have been obtained through the other steps, to analyse the staff members' knowledge about practices related to HCW adopted in the institution and to observe the adequacy between discourse and practice.

The best survey instrument for interviews is the Waste Management of Health Services - a rapid assessment tool proposed by the WHO whose Brazilian version was translated and validated by Silva (2011).

Due to the broad scope of this instrument, we recommend only using tool $D$, which is focused on obtaining data and information from the hospital managers, the nurses responsible for hospital infection control and the HCW manager.

Among the results, the researcher should know the level of knowledge of the respondents regarding current legislation and HCWM.

\section{EXAMPLE OF PROTOCOL APPLICATION}

In this section, a case study conducted in Rio de Janeiro, Brazil, demonstrates the applicability and effectiveness of the proposed HCWM protocol.

\subsection{Characteristics of the hospital analysed}

The hospital analysed is considered a reference facility for obstetrics and has the following sectors: Pre-delivery,
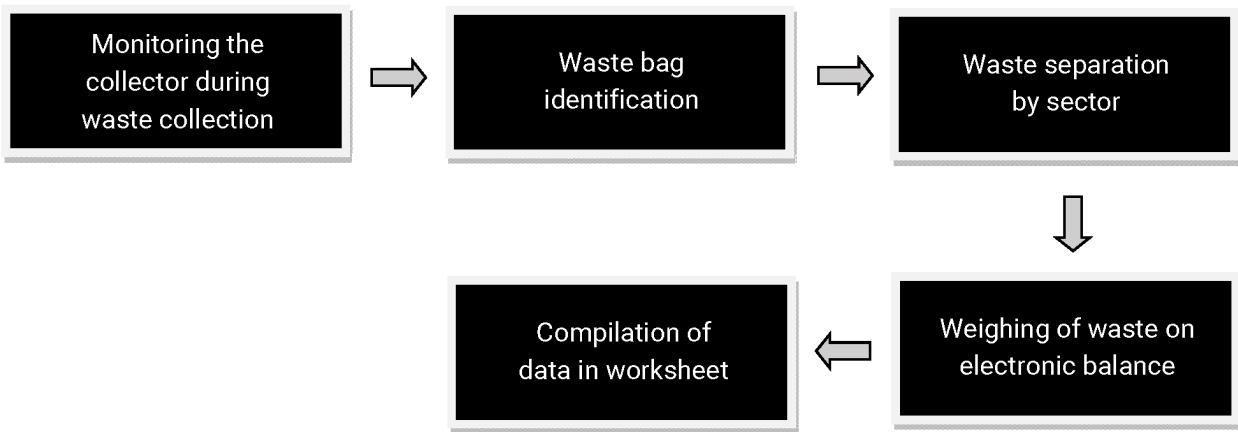

FIGURE 1: Steps of HCW quantification. 
TABLE 1: Classification of Brazilian HCW.

\begin{tabular}{|c|c|}
\hline Groups & Description/examples \\
\hline$A$ & $\begin{array}{l}\text { Wastes that represent risk to public health and the environ- } \\
\text { ment due to presence of biological agents such as: blood, } \\
\text { bodily fluids, drainage fluids or excreta. Ex. surgical gloves, } \\
\text { gauze, cotton, bandages; laboratory plates and blades and } \\
\text { vaccines discarded. }\end{array}$ \\
\hline B & $\begin{array}{l}\text { Wastes that represent risk to public health and the environ- } \\
\text { ment, due to their characteristics of inflammability, corrosive- } \\
\text { ness, reactivity and toxicity. } \\
\text { Ex. some chemical products and pharmacological substanc- } \\
\text { es }\end{array}$ \\
\hline $\mathrm{D}$ & $\begin{array}{l}\text { Common waste represented by non-recyclable waste (organic } \\
\text { waste) and recyclable waste ( paper, plastic etc.) }\end{array}$ \\
\hline $\mathrm{E}$ & $\begin{array}{l}\text { Sharp waste (used or unused syringes, butterfly needles, } \\
\text { lumbar puncture and cannula needles) }\end{array}$ \\
\hline
\end{tabular}

delivery and postpartum (PPP); Green; Lilac; Reception; Surgery Centre (SC); and Ambulatory. The PPP sector is where normal deliveries occur and it has 12 operating rooms, 2 nursing posts, 1 equipment room, 2 washbasins and 1 new-born room. In turn, SC has 2 operating rooms, 1 nursing post, 1 aesthetic recovery room, 1 equipment room, 1 new-born room and 3 washbasins. This is where caesarean deliveries are performed.

Regarding the Green and Lilac areas, they are where the parturients and their babies remain for about three days until hospital discharge. Green has 34 beds, 1 medication room, 1 nursery, 1 nursing post, 1 darkroom and 1 newborn room, while the Lilac has the same number of beds, 1 medication room and 1 nursing post. Reception is the place where patients register and any necessary initial care is provided. This place has 1 service desk, 1 hall and 1 baby changing room. The Ambulatory sector has 14 offices, 1 hall, 2 new-born changing room and 9 other rooms. It is where outpatients are attended, mainly pregnant in prenatal care and mothers and new-born children.

\subsection{HCW generation in July and August}

For this study, we decided to apply the quantification and gravimetric characterization steps for seven days in July and August, months which had the highest number of deliveries in recent years. However, in July we did not receive authorization for gravimetric characterization. Because of that, we performed quantification and gravimetric characterization in August.

Figure 2 presents the HCW generation $(\mathrm{kg} / \mathrm{d})$ in July and August.

The most representative sector in terms of total mass is the PPP, whose generation increased slightly between July and August. From the flow of the patients, we noted that the PPP is the sector where the vaginal deliveries are performed, a procedure that is the specialty of the hospital unit, corresponding to about of $75 \%$ of deliveries.

This type of delivery is associated with greater amounts of waste generated compared to caesarean delivery. In addition, the greater need for materials such as gauze bandages can explain the greater significance of this sector in terms of HCW generation.

Based on the results of the HCW quantification $(\mathrm{kg} / \mathrm{d})$, we noticed that although waste monitoring for two weeks only is too brief to capture seasonal changes, it is possible to learn the most representative sectors regarding HCW generation.

\subsection{Contribution by sector - Group D (common waste)}

Figure 3 shows the contribution by sector of common waste.

Reception is the sector with the main contribution of non-hazardous waste generation. This sector receives emergency care patients and consequently has a high turnover of pregnant women. Furthermore, this sector is used to store wastes from administrative areas (reception desk and management rooms).

In both July and August, the least significant sectors in the common waste generation were respectively the SC and Ambulatory. This may be related to the types of procedures performed in these sectors. The SC is an isolation area aimed at obstetrical procedures where the most significant waste masses consist of materials that can contain pathogens and pose a risk of disease transmission, such as gauze bandages, compresses contaminated with blood and other body fluids, all of which are classified as infectious waste (if there is no failure in segregation). The fact that the SC sector's contribution is lower than that of the PPP, although they are sectors with the same purpose, can be attributed to the fact that in the SC there are only two surgical rooms while in the PPP there are 12 rooms for deliveries.

In relation to Ambulatory, the main procedures were focused on queries posed to a multi-professional team, so this sector does not generate a significant amount of common waste.

\subsection{Contribution by sector - Group A (infectious waste)}

The same type of evaluation was carried out regarding the participation of each sector in the generation of infectious waste. The results are presented in Figure 4.

Among the sectors, the Reception presented the largest increase in the contribution of infectious waste, from $4 \%$ to $9 \%$. This increase was caused by a change in the types of services performed in this sector due to the overcrowding of the hospital and the increase in the number of emergency patients. This meant more frequent deliveries in this sector, changing the types of infectious wastes, in particular increasing the volumes of gloves, gauze bandages and compresses with blood that could contain pathogens and could be a risk of disease transmission if not properly stored.

The predominance of the PPP and SC in infectious waste generation is related to the obstetrical procedures performed in these sectors, with a considerable influence on the characteristics of HCW generated. These wastes are usually composed of materials such as compresses and gauze bandages contaminated with blood and other organic fluids.

\subsection{Interviews}

The interviewees were selected based on the details of tool D, which refers to the director of the hospital, the head 
se

\section{sc}

Analyzed sectors

FIGURE 2: HCW generation $(\mathrm{kg} / \mathrm{d})$.

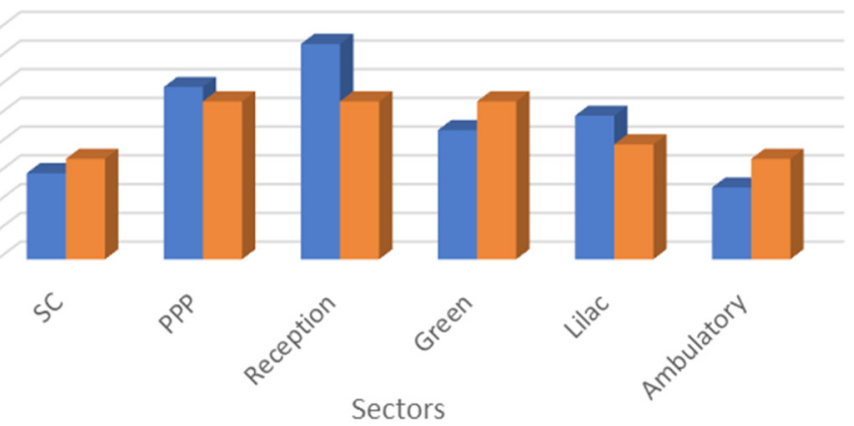

auly august

FIGURE 3: Common waste generation.
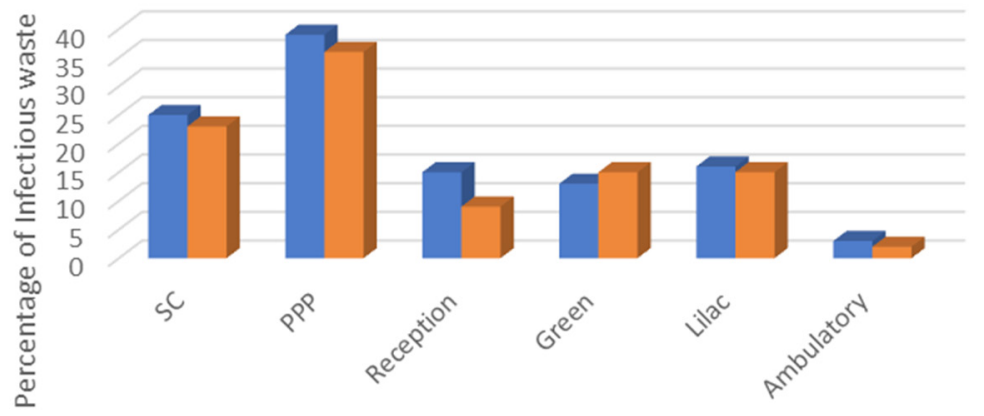

Sectors

FIGURE 4: Infectious waste generation.

nurse for infection control and the HCWM manager. The main results are presented in the sections below.

\subsubsection{Interview with health institution manager}

Table 2 presents some items of the questionnaire in which the interviewee's answers served to corroborate the information obtained by the previous data collection tools.

According to the institution's manager, the hospital is officially classified in the National Registry of Health Establishments as an institution with medium complexity, but in practice it should be classified as having high complexity, based on the following argument:

"In practice the hospital can be considered highly complex, because it caters to all the patients who come here. It should be a closed-door hospital, which would reduce its complexity, but this is not what happens in practice. There is greater control in the outpatient clinic, but not in the hospital."

Thus, the hospital ends up being basically an "open door" hospital, especially for pregnant women in the region, and this may be one of the explanations for the manager's response about the number of beds occupied. In this statement, the respondent established in approximate numbers what was observed during the period of observation, quantification and the gravimetric characterization of the sectors, namely overcrowding, exemplified by the fact that the Reception focused mainly on emergency care, reflected in the generation of postpartum absorbents most commonly found in the PPP and Lilac sectors.

In the team/staff item, according to the administrative manager, the training contemplates HCWM, under the responsibility of the nursing manager, who is also responsible for HCWM. 
The statement from the manager indicates what that everything that refers to $\mathrm{HCW}$ is under the responsibility of the nursing manager. This indicates there is no effective participation of the other sectors in HCWM.

According to the administrative manager, there was only one training session focused on the standardization of the Healthcare Waste Management Plan. This training was inadequate, since this document should be prepared according to the specific characteristics of the institution in which it will be implemented. In addition, there should be continuous training of employees, especially those who are responsible for the training of others.

\subsubsection{Interview with the nursing manager}

Table 3 shows the items and excerpts from the comments that provided evidence about the HCWM, facilitating triangulation of the results obtained in the other stages.

With regard to the number of beds occupied, the respondent was not certain about the right number.

As for hospital size, the respondent, despite not being able to specify the level of overload, tried to exemplify what had been observed in the institution and mentioned the maintenance of four more children in the Intensive Care Unit.

When questioned about the average number of outpatients and the number of outpatients attended per day, she again showed imprecision. Lack of information about the number of beds occupied and number of patients attended directly influences HCWM, since there is a positive correlation between the number of patients and $\mathrm{HCW}$ generation.

In the item staff/health professionals, the head nurse pointed out that all health professionals are immunized for hepatitis and tetanus. However, she did not know how many accidents with sharp objects had occurred in recent months. The low number of sharp object injuries in the hospital may be a reflection of the qualification process cited by the nurse or underreporting by staff, since the presence of syringes with bare needles among non-hazardous waste was noted during the gravimetric characterization.

Regarding the regulations on the Waste Management Plan, despite the nurse's response regarding training, she is not the person who manages the training of employees of the outsourced company, since they are trained by that company's nurse. Regarding this training, $\mathrm{COL} 1$ gave the following descriptions:

"The hospital rarely trains employees, and there is high employee turnover."

"It does not have specific training for waste; the company follows what the hospital does."

"I did not get training here, the way I work I brought from other places."

These comments reflect a lack of training in the institution. While stressing the fact that these training sessions were in line with the routine of the health establishment, he emphasized the lack of focus on HCW in this training.

COL 2, when asked about his work, responded as follows:

"I went in as a collector and they explained to me where the containers were, the need to wash the shelter and the walls. The service they taught me was a general service."

This indicates there was enumeration of the activities that should be performed and a basic explanation about containers' location and what they should store. However, there was no specific orientation for the collection activity,

TABLE 2: Interview with health institution manager.

\begin{tabular}{|c|c|}
\hline Question & Excerpt from the interviewee's response \\
\hline What type of institution and hierarchy level? & $\begin{array}{l}\text { "In practice the hospital can be considered highly complex, because it caters to all the patients who } \\
\text { come here." }\end{array}$ \\
\hline What is the number of beds occupied? & "There is an excess of demand, the hospital is overcrowded." \\
\hline Is there any type of training? & "You can get more information directly from the nursing manager." \\
\hline Is there any type of training for HCWM? & $\begin{array}{l}\text { "The only training received was about standardization of the Healthcare Waste Management Plan } \\
\text {..." }\end{array}$ \\
\hline What is the composition of HCWM? & "All the waste part is in charge of the nursing manager ..." \\
\hline How much financial resource is allocated to HCWM? & "... there should be a direction to decrease this percentage due to the scarcity of financial resources." \\
\hline
\end{tabular}

TABLE 3: Interview with nursing manager.

\begin{tabular}{l|l} 
Question & Excerpt from the interviewee's response \\
\hline How many beds are currently occupied? & "It's not easy to pinpoint, but you can call it overcrowded." \\
What is the average occupancy rate and number of \\
outpatients attended?
\end{tabular}


and training similar to that of a general service assistant was given.

\subsection{Gravimetric characterization of common waste (D)}

Gravimetric characterization of common waste in the Reception and PPP sectors is presented in Figure 5.

With regard to the figure, it is important to highlight that in the Reception area there was prevalence of paper and in PPP there was prevalence of plastics. Regarding paper, there was predominance of asepsis papers and toilet paper, a finding that may be related to the fact that it is an emergency care sector and consequently has a high turnover of pregnant women and a large number of hospital procedures. The waste paper found in the PPP was quite similar to that observed in the Reception, mainly composed of toilet paper and asepsis paper.

In the PPP, among the plastic waste most commonly observed, a contribution of $57 \%$ can be highlighted of absorbents used after childbirth. The presence of these absorbents is in accordance with the characteristics of the PPP. However, the main function of these absorbents is to contain bleeding. These wastes may contain pathogens and could be a risk of disease transmission, mainly because some patients are HIV positive and have hepatitis B.

The segregation of this type of waste as common waste shows failure in the training of health professionals, since this type of waste should be segregated and packaged in infectious waste bags.

Bloody postpartum absorbents mixed with common waste (37.5\% of the total plastic mass) was also noticed in the Reception sector.

As for plastic waste, we observed in both sectors the presence of potentially recyclable waste such as plastic cups, syringe packs and plastic bags. But we also observed some infectious waste that could contain pathogens such as serum bags and serum equipment. The presence of this waste indicates failure of the HCWM.

Another plastic waste observed was syringes without needles and syringes with capped needles. The presence of needled syringes indicates that employees do not follow the established disposal recommendation regarding sharp objects. Furthermore, the disposal of syringes without needles indicates that the professionals of this sector removed the needles, which is not recommended due to the possibility of accidents.

With regard to occupational risk, the simple segregation of syringes with bare needles as common waste places a considerable occupational risk on the people who handle the HCW.

\section{MANAGERIAL IMPLICATIONS}

This article is important for health institution managers, healthcare waste managers and researchers, by providing information to improve HCW management. The proposed protocol involves qualitative and quantitative tools, providing a useful, quick and practical assessment method that can be used by researchers and health managers to improve HCWM practices. Furthermore, application of the protocol built a database for health institutions about the evolution of HCWM over the years.

Among the main advantages of this protocol in comparison to the other ones, we can mention that it is based on evidence obtained by qualitative tools, such as interviews, questionnaires and observation, and by quantitative tools for characterization, in an attempt to minimize the limitations of each of the tools used.

Consequently, this protocol can provide detailed information about the breakdown of HCW generation by sector and by type, to support efforts to minimize and properly segregate and manage $\mathrm{HCW}$, in compliance with internal rules and general legislation and regulation. In addition, through the comments of health professionals involved in HCWM, it elicits information about their knowledge and practices, providing support for training programs.

\section{CONCLUSIONS}

In this paper, we propose and report the application of an integrated protocol to provide qualitative and quantitative information about HCWM, using literature review as a guide. Furthermore, the protocol can provide some basic methods for managers to implement HCWM in health establishments that do not have a formal procedure and to improve practices in institutions that already have a HCWM program.

A case study was presented to demonstrate the principal results obtained using this protocol. In general, the

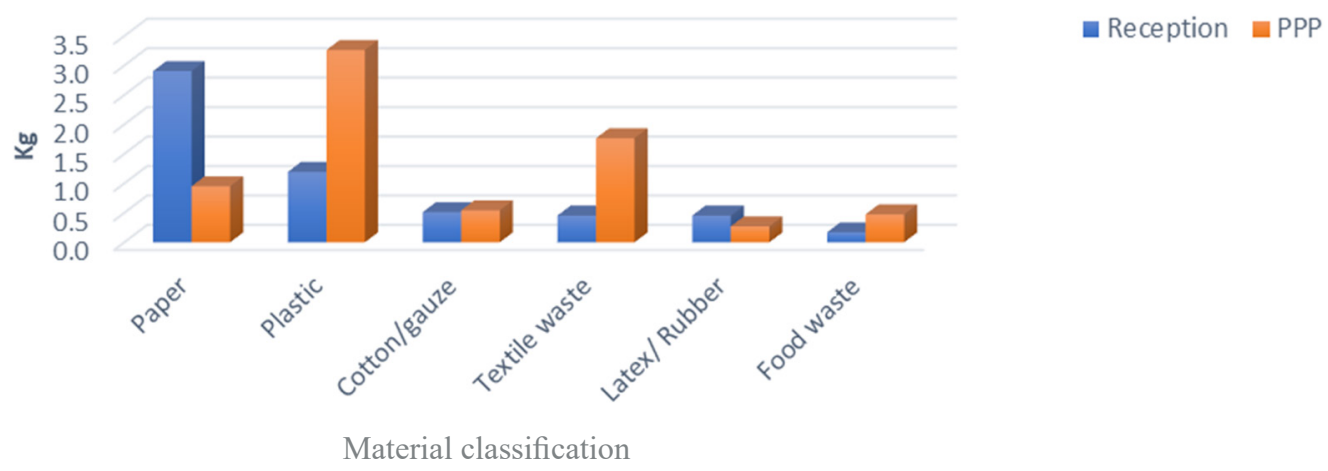

FIGURE 5: Gravimetric characterization. 
application of the protocol was satisfactory, since even with the adaptation of the protocol to the hospital's reality, all the proposed steps were carried out and the expected results in each of the steps were obtained.

Although the proposed protocol was developed to be applied in any health unit, future studies will be carried out in health units with different characteristics. We hope this protocol will be applied in both developing and developed countries and improvements will be made by other authors and health professionals.

Other studies can focus on the information obtained by the protocol and create a forecast model for the generation and composition of HCW in order to provide support to improved management.

\section{ACKNOWLEDGEMENTS}

We thank the entire staff of the hospital for the important contribution given during the development of the study. We also thank the National Council for Scientific and Technological Research (CNPq) for financial support.

\section{REFERENCES}

Aduan, S.A.; Braga, F.S.; Zandonade, E.; Salles, D.C.; Noil, A.M.; Lange, L.C. ,2014 Avaliação dos resíduos de serviços de saúde do Grupo A em hospitais de Vitória (ES), Brasil. Engenharia Sanitária e Ambiental Rio de Janeiro, v. 19, n. 2, p. 413-420

Ali, M., Wang, W., Chaudhry, N., Geng, Y., \& Ashraf, U.,2017. Assessing knowledge, performance, and efficiency for hospital waste management-a comparison of government and private hospitals in Pakistan. Environmental monitoring and assessment, 189(4), 181.

André, S. C. D. S., Veiga, T. B., \& Takayanagui, A. M. M.,2016. Generation of Medical Waste in hospitals in the city of Ribeirão Preto (SP), Brazil. Engenharia Sanitaria e Ambiental, 21(1), 123-130.

Anozie, O. B., Lawani, L. O., Eze, J. N., Mamah, E. J., Onoh, R. C., Ogah, E. O., ... \& Anozie, R. O.,2017. Knowledge, Attitude and Practice of Healthcare Managers to Medical Waste Management and Occupational Safety Practices: Findings from Southeast Nigeria. Journal of clinical and diagnostic research: JCDR, 11(3), IC01.

ANVISA, 2004. National Health Surveillance Agency. Resolution No. 306, December 2004. (Adopts provisions concerning technical regulation for managing healthcare waste). http://portal.anvisa.gov. br/documents/33880/2568070/res0306_07_12_2004.pdf/95eac678-d441-4033-a5ab-f0276d56aaa6 (accessed May 2018).

Aseweh Abor, P., 2013. Managing healthcare waste in Ghana: a comparative study of public and private hospitals. International journal of health care quality assurance, 26(4), 375-386.

Awodele, O., Adewoye, A. A., \& Oparah, A. C.,2016. Assessment of medical waste management in seven hospitals in Lagos, Nigeria. BMC public health, 16(1), 269

Centro Pan-Americano de Engenharia Sanitária e Ciências do Ambiente, 1997. Guia para manejo interno de resíduos sólidos em estabelecimentos de saúde. Organização Pan-Americana da Saúde. Brasília. http://www.bvsde.paho.org/cursoa_reas/e/fulltext/reshospi. pdf (accessed May 2018)

CONAMA, 2005. National Environmental Council. Resolution No. 358, April 2005. (Adopts provisions concerning treatment and disposal of waste of healthcare services).http://www.mma.gov.br/port/ conama/legiabre.cfm?codlegi=462 (accessed May 2018).

Debere, M. K., Gelaye, K. A., Alamdo, A. G.,Trifa, Z. M., 2013. Assessment of the health care waste generation rates and its management system in hospitals of Addis Ababa, Ethiopia, 2011. BMC Public Health, 13(1), 28.

Ghafuri, Y., \& Nabizadeh, R. ,2017. Composition and quantity of cytotoxic waste from oncology wards: A survey of environmental characterization and source management of medical cytotoxic waste. BIOSCIENCE BIOTECHNOLOGY RESEARCH COMMUNICATIONS, $10(3), 438-444$.
Hadipour, M., Saffarian, S., Shafiee, M., \& Tahmasebi, S.,2014. Measurement and management of hospital waste in southern Iran: a case study. Journal of Material Cycles and Waste Management, 16(4), 747-752.

Idowu, I., Alo, B., Atherton, W., \& Al Khaddar, R., 2013. Profile of medical waste management in two healthcare facilities in Lagos, Nigeria: a case study. Waste Management \& Research, 31(5), 494-501.

Koolivand, A., Mahvi, A. H., Alipoor, V., Azizi, K., \& Binavapour, M.,2012. Investigating composition and production rate of healthcare waste and associated management practices in Bandar Abbass, Iran. Waste Management \& Research, 30(6), 601-606.

Kumar, R., Gupta, A. K., Aggarwal, A. K., \& Kumar, A.,2014. A descriptive study on evaluation of bio-medical waste management in a tertiary care public hospital of North India. Journal of Environmental Health Science and Engineering, 12(1), 69.

Kumar, R., Shaikh, B. T., Somrongthong, R., \& Chapman, R. S.,2015. Practices and challenges of infectious waste management: A qualitative descriptive study from tertiary care hospitals in Pakistan. Pakistan journal of medical sciences, 31(4), 795.

Longe, E. 0.,2012. Healthcare waste management status in Lagos State, Nigeria: a case study from selected healthcare facilities in Ikorodu and Lagos metropolis. Waste Management \& Research, 30(6), 562-571.

Malekahmadi, F., \& Yunesian, M.,2014. Analysis of the healthcare waste management status in Tehran hospitals. Journal of Environmental Health Science and Engineering, 12(1), 116.

Moreira, A. M. M., \& Günther, W. M. R.,2012. Assessment of medical waste management at a primary health-care center in São Paulo, Brazil. Waste Management, 33(1), 162-167.

Oli, A. N., Ekejindu, C. C., Adje, D. U., Ezeobi, I., Ejiofor, O. S., Ibeh, C. C., \& Ubajaka, C. F. 2016. Healthcare waste management in selected government and private hospitals in Southeast Nigeria. Asian Pacific Journal of Tropical Biomedicine, 6(1), 84-89.

Oroei, M., Momeni, M., Palenik, C. J., Danaei, M., \& Askarian, M.,2014. A qualitative study of the causes of improper segregation of infectious waste at Nemazee Hospital, Shiraz, Iran. Journal of infection and public health, 7(3), 192-198.

Oyekale, A. S., \& Oyekale, T. 0.,2017. Healthcare waste management practices and safety indicators in Nigeria. BMC public health, 17(1), 740.

Sartaj, M., Arabgol, R., 2015. Assessment of healthcare waste management practices and associated problems in Isfahan Province (Iran).Journal of Material Cycles and Waste Management, 17, 1, 99-106.

Sharma, S. K., \& Gupta, S.,2017. Healthcare waste management scenario: A case of Himachal Pradesh (India). Clinical Epidemiology and Global Health, 5(4), 169-172.

Silva, E. N. C.,2011. Gerenciamento de Resíduos de Serviços de Saúde: adaptação transcultural e validação do instrumento Health-care Waste Manegement - Rapid Assessment Tool.2011. Tese (Doutorado) - Escola Nacional de Saúde Pública, Rio de Janeiro. https:// www.arca.fiocruz.br/bitstream/icict/17974/1/218.pdf (accessed May 2018)

Souza, T. C., Oliveira, C. F. D., \& Sartori, H. J. F.,2015. Diagnostic management of medical waste in public establishments of municipalities that receive Ecological ICMS in the State of Minas Gerais. Engenharia Sanitaria e Ambiental, 20(4), 571-580.

Tadesse, M. L., Kumie, A., 2014. Healthcare waste generation and management practice in government health centers of Addis Ababa, Ethiopia. BMC public health, 14, 1, 1221.

Tesfahun, E., Kumie, A., Legesse, W., Kloos, H., \& Beyene, A., 2014. Assessment of composition and generation rate of healthcare wastes in selected public and private hospitals of Ethiopia. Waste Management \& Research, 0734242X14521683.

Zhang, H. J., Zhang, Y. H., Wang, Y., Yang, Y. H., Zhang, J., Wang, Y. L., Wang, J. L., 2013 Investigation of medical waste management in Gansu Province, China. Waste Management \& Research, 31(6), 655-9. 